\title{
HEALTH PROMOTION AND PREVENTION IN OCCUPATIONAL HEALTH SYSTEMS IN EUROPE
}

\section{PIOTR SAKOWSKI and ANDRZEJ MARCINKIEWICZ}

\author{
Nofer Institute of Occupational Medicine, Łódź, Poland \\ Department of Occupational Diseases and Environmental Health
}

\begin{abstract}
Objectives: In the contemporary Western culture, working population health issues, stressed in various publications, have been perceived as a crucial part of public health. To deal with occupational health issues properly, occupational health services (OHS), aiming at the protection of the workers' health, are organized in many countries. The survey was to find the differences in occupational health systems that the European Economic Area countries use in order to execute prophylactic activities focused on diseases of affluence and how the OHS are used for health promotion actions. Material and Methods: The survey was conducted with the use of an on-line expert questionnaire. No deep statistical analysis was performed as for the designed aims of the study simple statistics were sufficient. Results: All the reviewed countries have organized OHS. The funding mechanisms are based mainly on the financial involvement of employers. In the majority of countries, the main goal of the OHS is certification of the ability to work. Workplace surveillance aiming at the occupational risk assessment and health promotion activities that focus on work-related and/or occupational diseases are the most popular services provided within national systems. Conclusions: Occupational health professionals are well placed to perform actions directed at health promotion and prophylactics of a wide range of diseases - not only occupational/work-related, but also non-communicable, particularly lifestyle-related diseases of affluence. The engagement of the occupational medical services (OMS) in prevention of the non-work-related health issues would be valuable. However, it would be inevitable for employers to finance a wider range of services to a greater extent. Int J Occup Med Environ Health. 2019;32(3):353-61
\end{abstract}

Key words:

health policy, health promotion, occupational health services, primary prevention, secondary prevention, diseases of affluence

\section{INTRODUCTION}

In the contemporary Western culture, issues related to the health of the working population, perceived as a crucial part of public health, have been stressed in publications and documents issued by important stakeholders, like the World Health Organization (Global Plan of Action on Workers' Health 2008-2017) [1], the European Union (Framework Directive on Occupational Safety and
Health) [2] or the International Labor Organization (ILO), activities of which are mostly focused on occupational health and safety. To deal with occupational health issues properly, countries organize occupational health (and safety) services in a way which allows them to involve occupational health professionals and let them act independently aiming at protecting the workers' health. The International Labor Organization provides 2 labor standards referring

\footnotetext{
Funding: this study was supported by the Nofer Institute of Occupational Medicine (project No. IMP 12.25 entitled "Analysis of organizational and legislative solutions in occupational health systems in the chosen EU countries with particular consideration of work-related diseases prophylactics and work-life prolongation," project manager: Piotr Sakowski, M.P.H.).

Received: September 12, 2018. Accepted: September 28, 2018.

Corresponding author: Piotr Sakowski, Nofer Institute of Occupational Medicine, Department of Occupational Diseases and Environmental Health, św. Teresy 8 , 91-348 Łódź, Poland (e-mail: piotr.sakowski@imp.lodz.pl).
} 
directly to such services - the Occupational Health Services Convention no. 161 [3] and the Occupational Health Services Recommendation no. 171 [4], which, in brief, concern the organizational structure and functioning of such services. In Europe, even though only 17 (or 18, if we include Turkey) countries have ratified Convention no. 161, all the states have developed some kind of occupational health policy, which differs in terms of the formalization and organization pattern of structures designed to perform the occupational health oriented tasks.

According to the latest Eurostat data, the total population of the European Union was estimated at 510 million people, with 239 million of active population aged 15-64 years old, and more than 218 million of those who were employed (aged 15-64) [5]. Almost $43 \%$ of all the EU residents constitute a possible target group for the activities of the occupational health services (OHS). The term "possible" has been used with reference to the target group because not all countries use the OHS on a mandatory basis for the whole working population. Taking into account the fact that the OHS consists of health professionals competent in providing health care not only in that specific field, but they are also able to initiate actions aiming at general health issues, it seems obvious that the OHS might easily contribute to the health improvement of general population as well as public health.

The aim of the research team was to find differences in the occupational health systems that the European Economic Area (EEA) uses to execute prophylactic activities focused on diseases of affluence and how the OHS might be used for health promotion actions.

\section{MATERIAL AND METHODS}

The available documents and grey literature regarding individual occupational health systems in the EEA countries include important and useful information, however, they do not provide detailed information about specific activities performed within those systems. That is why an on-line expert questionnaire method for collecting information has been chosen. The web-based approach is highly recommended by the WHO for similar Key Informant Surveys [6]. The questionnaire consisting of 26 questions was pre-tested and the version of the tool with 19 closed and open questions regarding occupational safety and health systems was completed. The pilot-testing and validation were based on responses (pre-filling of the questionnaire) and comments from 4 experts from 2 countries (not the ones chosen for the core phase of this study), which allowed to optimize the tool by deleting questions irrelevant to the main goal of this study and re-phrasing questions and possible responses to make them more precise.

The questionnaire expands the existing knowledge in such aspects as: availability of and access to occupational medical services (OMS), the scope and goal of services provided, results (including formal ones) and funding sources. The link to the questionnaire, together with a cover letter explaining the aims of the survey and with a request to contribute to the survey by completing the online questionnaire form was afterwards e-mailed to experts from 29 countries in the EEA. The choice of experts was based on the identification of individuals experienced in the research in the area of occupational health organization and functioning of the OHS, who were related to recognized institutions operating in the field of interest. The respondents were identified via existing networks (Baltic Sea Network on Occupational Health and Safety, South East European Network on Workers' Health, Northern Dimension Partnership in Public Health and Social Wellbeing), research institutions and governmental and public bodies responsible for occupational health (ministries, inspections, authorities). The replies began to be sent in the 4th quarter of 2016 and the last were received at the end of the 3rd quarter of 2017, including several reminders. No deep statistical analysis was performed, as for the designed aims of the study simple statistics were sufficient. No ethical approval was required due to the fact that this 
study did not meet the criteria of standard experiments on living human subjects, as no human biological material, no health records and no other sensitive data was collected or processed.

\section{RESULTS}

The research team received replies from experts representing 17 countries: Austria, Bulgaria, Croatia, Czech Republic, Estonia, Finland, France, Germany, Greece, Hungary, Italy, Lithuania, Netherlands, Norway, Poland, Spain and the United Kingdom. Taking into account the regional coverage, these replies allow to present the description of the approach to prophylactic activities and health promotion in the OHS in the majority of the EEA's territory.

With reference to the system conditions of provision of the OMS within the occupational safety and health (OSH) system, in 10 countries the provision of such services is obligatory, in 5 countries providing the OMS within the OSH system has pre-defined obligatory scope, and additional services may be offered on a voluntary basis whereas 2 states allow for voluntary provision, based mainly on contracts between the OHS units and payers. It was also stressed by 2 experts that there might have been an issue with proper practical implementation of legislation, which results in obstructed provision of medical services. The concept of who should be covered by the OMS has dichotomous characteristics: in 10 countries only employees (i.e., those who have an employment contract) are eligible to receive the OMS in the occupational safety and health system, while in 7 countries all workers (i.e., working people) are entitled to benefit from the OMS.

The scope of services provided by the OMS units results mainly from the country legislation. This happens in the case of 14 countries. The legislation provisions are supported by contracts between service providers and various entities: contractors (i.e., those who pay for services) and/ or clients (those who use services). Such a situation may be observed in 8 out of those 14 countries which derive the scope of their OMS units' services from legislation, and also in 3 states which base the scope only on provisions of contracts.

As far as the funding of the OHS is concerned, 1 country (Greece) involves state budget into participation in costs of occupational health services. One country (Croatia) has also designed its funding policy on financing the services by an insurance institution. Two countries (Finland and Greece) assume payments from both employers and employees. In 6 cases, the involvement of insurance institutions is expected to supplement financial input from employers and/or employees. However, the most popular mechanism of financing occupational health services is based on financial involvement of employers, who are either the only or the main payers. This solution was observed in 15 out of 17 analyzed countries. It should be stressed that although some countries use mixed mechanisms of funding the OHS, employers still remain the main payer.

The identification of the main goals of the OMS within the OSH systems in various countries as well as the range of services provided varies slightly. In the majority of countries, the main goal of the OMS is the certification of the ability (or lack of ability) to perform work at a given workplace. This is observed in 9 states. In 2 countries, the major goal is diagnosing and treatment related to harmful factors at the workplace, and experts from the remaining 6 countries included in this analysis mentioned the following additional goals: health surveillance, advisory and educational activities for both employers and employees, early diagnosis and prevention of work related diseases.

From what the experts claim, it seems that conducting the certification process of ability to work is yet the most prominent goal for the OMS in the majority of analyzed countries.

Taking into account the activities covered by the OSH systems in various countries, workplace surveillance aim- 


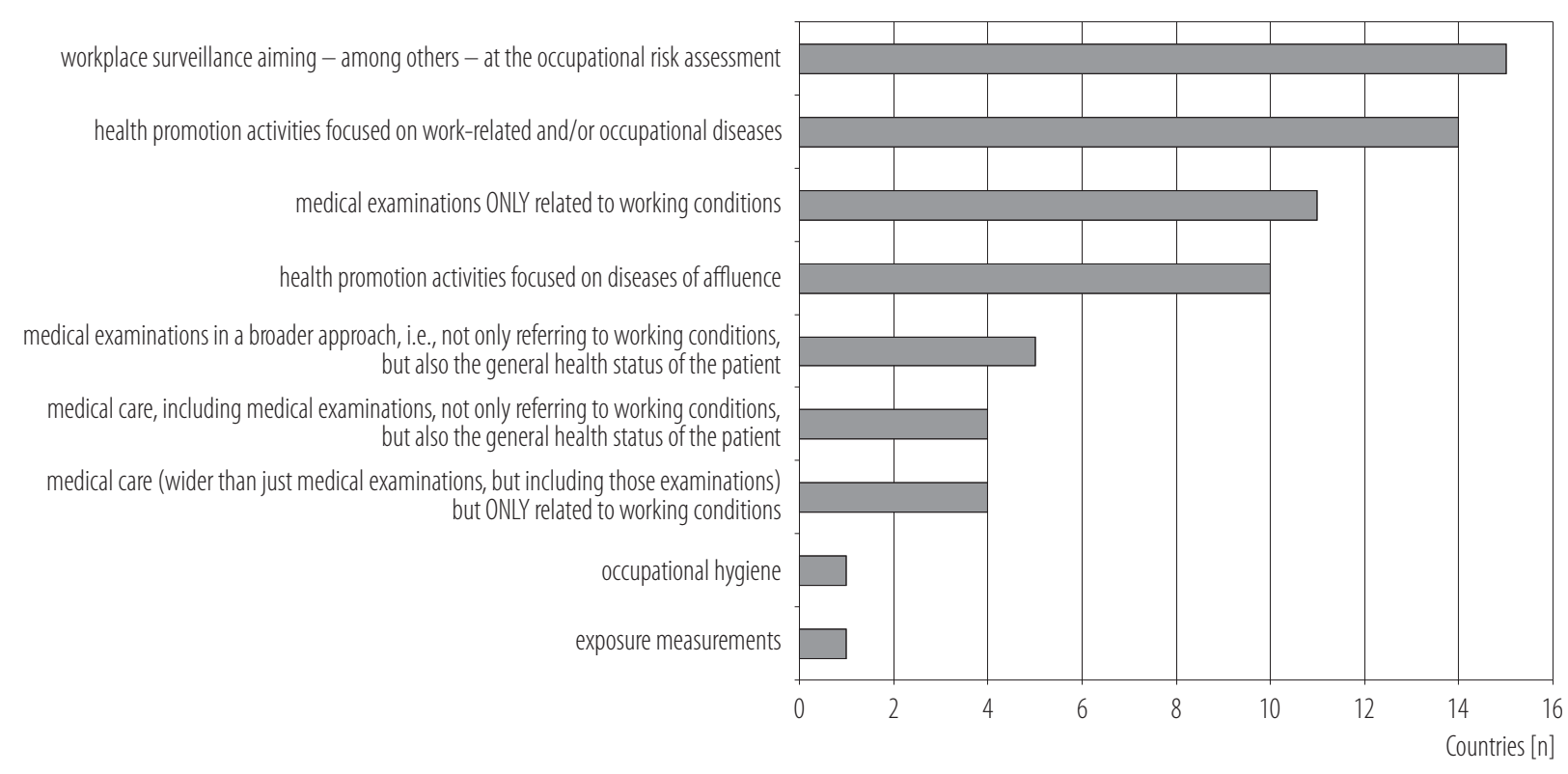

Figure 1. Number of countries in which a specific type of service is provided based upon the study "Analysis of organizational and legislative solutions in occupational safety and health (OSH) systems in the chosen EU countries with particular consideration of work-related diseases prophylactics and work-life prolongation" conducted in 2016-2017 in the area of occupational health policy

ing, among others, at occupational risk assessment, and health promotion activities focused on work-related and/ or occupational diseases are the most popular services provided within national systems. The Figure 1 shows distribution of experts' answers to the question about services which are covered by the OSH system. Respondents were allowed to choose more than 1 answer, which is the reason why answers in the Figure 1 sum up to more than 17.

An interesting observation relates to the results of certification of ability to perform work at a specific workplace. There are 2 major consequences of such certification which result in formal obligations:

- issuing a decision stating that a given person is allowed or is not allowed to work (selection of a worker for work) - observed in 5 countries - Croatia, the Czech Republic, Hungary, Norway, Poland;

- issuing binding information for an employer which defines steps to be undertaken to make work possible for a given worker (obligatory adaptation of work to work- er's needs) - observed in another 5 countries - Austria, Estonia, France, Italy, Lithuania. Additionally, in 3 countries (Finland, the Netherlands, Spain) certification is related to issuing non-binding information for an employer which defines steps that may be undertaken to make work possible for a given worker, which may be regarded as a recommendation to adapt work to the worker's needs.

Apart from the above-mentioned approaches, 4 countries present their own, tailor-made concepts.

The OMS issues a decision stating that a given person is allowed or is not allowed to work on the basis of preliminary medical checks, but if changes in health occur after working for some time, the employer is obliged to adapt the workplace or propose another workplace, the employee is informed about the risk, but is not obliged to accept the employer's proposal (Bulgaria).

Two countries (Germany and Greece) present a mixed approach: issuing a decision which states that a given person is allowed or is not allowed to perform certain tasks or 


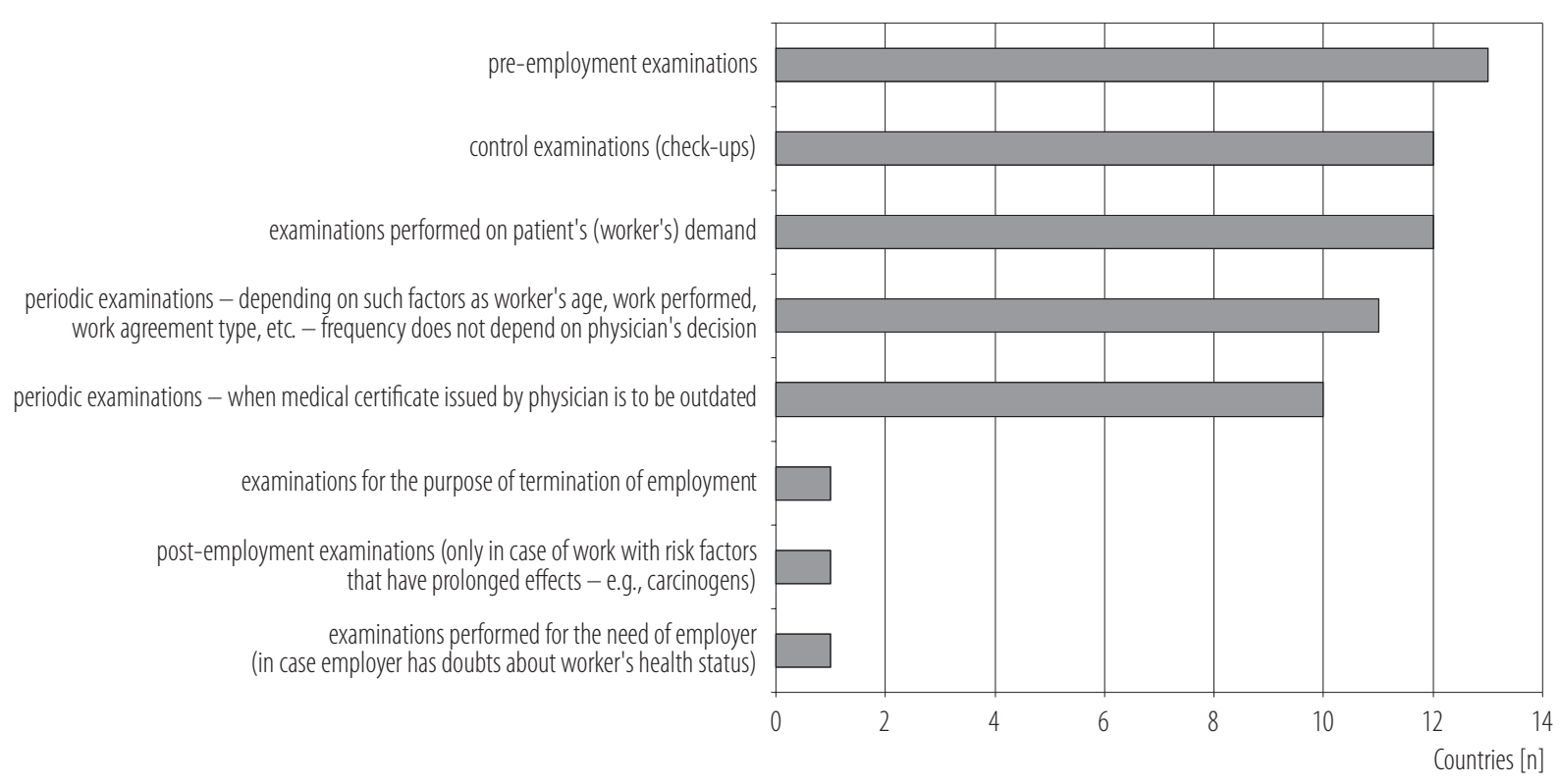

Figure 2. Number of countries in which specific medical examinations are covered by the occupational safety and health (OSH) system based upon the study "Analysis of organizational and legislative solutions in occupational health systems in the chosen EU countries with particular consideration of work-related diseases prophylactics and work-life prolongation" conducted in 2016-2017 in the area of occupational health policy

work or to hold a certain work position, as well as issuing non-binding information for employer regarding steps that may be undertaken to make work possible for a given worker.

In the United Kingdom the formal result of certification depends on certain circumstances, like a type of industry - in some industries, e.g., railway or offshore industry, workers must be certified as fit for work, while in others, the certification is more likely to be advisory based, for example, on a "return to work" plan.

The research team asked about types of medical examinations covered by the OSH system. The results are shown in the Figure 2. Respondents were again allowed to choose more than 1 answer.

\section{DISCUSSION}

Studies based on a similar method (expert surveys, Key Informant Surveys) have been commonly used for collecting information and research in the field of health systems organization [6-10]. Using a valid approach recognized by respondents, selection of well-informed experts as respondents, and an important public health issue covered by the research, may be regarded as an advantage of this study. The response rate may also be treated as a strong point because replies allow the research team to describe an approach to prophylactic activities and health promotion in the OHS in the majority of EEA's territory. However, on the other hand, missing responses from 12 countries constitute a certain limitation, which does not allow the authors to generalize responses or conclusions for the whole EEA. The selection of individual experts may also be a source of potential bias, which research team endeavored to minimize by the appropriate construction of the questionnaire.

The findings of this study reveal that all reviewed countries have developed occupational health policies. An important thing is that the scope of services provided within the OSH system does not necessarily have to be described 
in details in the country legislation in order to be properly implemented. However, the popular trend seems to be based on legislation supported by business contracts detailing the scope of provided services. Although only 7 out of the discussed countries have ratified ILO Convention no. 161 [3], it seems that all of them do implement the functions of the OHS described in Article 5 of the Convention in practice. The obligation of the employers to be responsible for their workers' health and safety at the company level [2,3] is reflected in the employers' financial involvement in funding the OHS in almost all countries.

We would like to emphasize that although the OMS realize the tasks related to health and safety at work (like workplace surveillance aiming at occupational risk assessment, health promotion activities focused on work-related and/or occupational diseases, or medical examinations related to working conditions) very well, there are also activities that lie slightly out of the main stream of interest of the OHS and for which occupational health professionals are very well suited.

The idea that the OHS may contribute not only to occupational health area, but also to other public health fields has already been mentioned in the Basic Occupational Health Services concept and related publications [11,12]. The concept of integrating all possible actions aiming at the improvement of public health has become common and stressed in the policy papers of the most important stakeholders in the field of health, and the idea of using the OHS for health promotion and prophylactic activities may be found in or inferred from numerous policy papers and publications starting from Alma Ata Declaration on Primary Health Care [13], Ottawa Charter for Health Promotion [14], through the EU Second [15] and Third [16] Programmes for the Union's action in the field of health, strategic plan 2016-2020 by DG Health and Food Safety [17], to the Health in All Policies concept-related texts, to list just a few [18-20].

The workplace and the OHS constitute a very important arena for actions supporting the improvement of the working population health. Taking into account the fact that in the majority of European countries provision of the OHS seems to be obligatory, an assumption may be made that once in a specific period of time a working person would see an occupational health professional whereas he or she may not see any primary health physician for years. Hence, using the OMS for health promotion, not limiting its activities only to workplace health promotion, but considering its wider meaning, particularly focusing on diseases of affluence, some chronic conditions, or lifestyle, may become an effective way of general population health status improvement. Considering occupational health professionals' expertise and experience, they are very well suited to initialize disease prevention and health promotion actions. Physicians are regarded as those individuals who are able to effectively modify the behavior of their patients [21-23]. The authority of occupational physicians should be a benefit in contact with the patient (i.e., worker), however they should be also aware of possible barriers to be overcome, similarly to other groups of physicians who communicate with patients [21,24-26].

Taking into account the results of this survey, in particular the scope of services already provided, the extent of examinations performed within the OMS, the goals of the OSH systems, keeping in mind funding mechanisms for the OHS, we would like to imply that health promotion and preventive activities should become more existent in every-day functioning of the OMS units. Health promotion activities focused on diseases of affluence have already been present in the OMS practice in ten countries, and medical examinations in a broader approach, i.e., not only referring to working conditions, but also to the general health status of the patient, have been conducted in 5 states. Examinations performed on the patient's (worker's) demand have also appeared in practice in 12 countries. We claim there is a need for the involvement of occupational health professionals into non-occupationally-related health prevention to a greater extent in order to contribute to the greater wellbeing of all working people in terms of the improvement 
of their health status. A visible characteristics of the contemporary European labor market is a prolonged working life, which is one of the consequences of the increase of life expectancy in Europe. This obviously positive phenomenon generates some challenges for societies and social security and health systems. Individuals are expected to be fit for work for a longer period of time than several years ago, which demands a revised approach from entities responsible for the protection of health and social wellness.

The occupational health services through actions focused on the prevention of both occupational/work-related diseases and non-communicable diseases, particularly lifestyle-related diseases of affluence, may play an important role in public health protection. Yet, funding is an issue not to be forgotten in these considerations. Taking into account that in the majority of countries services provided within the OSH system are paid mainly or only by the employers, all involved stakeholders - policy makers responsible for health and social security systems, representatives of occupational health professionals and occupational health institutions - should make an attempt to convince the employers to invest in the health of their employees to a slightly greater extent. The results of this research may serve as an argument in public discussion or implicit operations undertaken by various stakeholders involved in the occupational health policymaking process aiming at the improvement of the national OSH systems.

\section{CONCLUSIONS}

In the majority of countries, the main goal of the OMS is the certification of ability (or lack of ability) to perform work at a given workplace.

This certification, obligatory either for all workers or selected professional groups, requires recurring contacts with a physician, also in the case of those persons who do not often use health services or do not use them at all.

The occupational health services through actions focused on the prevention of both occupational and/or work-relat- ed diseases and non-communicable diseases, particularly life-style-related diseases of affluence, may play an important role in public health protection.

\section{REFERENCES}

1. Workers' health: Global plan of action. Sixtieth World Health Assembly. WHA60.26. [Internet]. World Health Organization; 2007 [cited 2017 Oct 18]. Available from: http://www. who.int/occupational_health/WHO_health_assembly_en_ web.pdf.

2. Council Directive 89/391/EEC of 12 June 1989 on the introduction of measures to encourage improvements in the safety and health of workers at work [Internet]. Off J Eur Communities L 183 (Jun 29, 1989) [cited 2017 Oct 18]. Available from: http:/eur-lex.europa.eu/legal-content/EN/ ALL/?uri=CELEX\%3A31989L0391.

3. International Labour Organization [Internet]. The Organization; c1996-2017 [cited 2017 Oct 18]. C161 - Occupational Health Services Convention, 1985 (No. 161). Available from: http://www.ilo.org/dyn/normlex/en/f?p=NORMLEXPUB:12 100:0::NO::P12100_ILO_CODE:C161.

4. International Labour Organization [Internet]. The Organization; c1996-2017 [cited 2017 Oct 18]. R171 - Occupational Health Services Recommendation, 1985 (No. 171). Available from: http://www.ilo.org/dyn/normlex/en/f?p=NORM LEXPUB:12100:0::NO:12100:P12100_INSTRUMENT_ ID:312509:NO.

5. Eurostat [Internet]. Eurostat [cited 2017 Oct 18]. Available from: http://ec.europa.eu/eurostat/data/database.

6. World Health Organization. Description of the Key Informant Survey [Internet]. The Organization; 2001 [cited 2018 Mar 14]. Available from: http:/www.who.int/responsiveness/ surveys/KIS_2001_Methodology.pdf.

7. Rantanen J, Lehtinen S, Valenti A, Iavicoli S. A global survey on occupational health services in selected International Commission on Occupational Health (ICOH) member countries. BMC Public Health. 2017;17(1):787, https://doi. org/10.1186/s12889-017-4800-z. 
8. De Silva A, Valentine N. Measuring responsiveness: Results of a key informants survey in 35 countries. GPE Discussion Paper No. 21 [Internet]. Geneva: World Health Organization; 2000 [cited 2018 Mar 14]. Available from: http://www. who.int/healthinfo/paper21.pdf.

9. Valentine NB, de Silva QA, Murray CJL. Estimating responsiveness level and distribution for 191 countries: Methods and results. GPE Discussion Paper Series: No. 22 [Internet]. Geneva: World Health Organization; 2000 [cited 2018 Mar 14]. Available from: http://www.who.int/healthinfo/pa per22.pdf.

10. Parsons JA, Baum S, Johnson TP. Inclusion of disabled populations in social surveys: Review and recommendations [Internet]. Chicago: National Center for Health Statistics, University of Illinois at Chicago; 2000 [cited 2018 Mar 14]. Available from: http://www.srl.uic.edu/Publist/ StdyRpts/838disability/DisabledPops.pdf.

11. Rantanen J. Basic Occupational Health Services (3rd revised edition) [Internet]. Helsinki: Finnish Institute of Occupational Health; 2007 [cited 2017 Oct 24]. Available from: https:// www.julkari.fi/bitstream/handle/10024/135069/Basic\%20Occupational $\% 20 \mathrm{Health} \% 20$ Services.pdf? sequence $=1$.

12. Rantanen J. Basic occupational health services - Their structure, content and objectives. Scand J Work Environ Health Suppl [Internet]. 2005 [cited 2017 Oct 24];1:5-15. Available from: http://www.sjweh.fi/show_abstract.php?abstract_ id $=927$.

13. Declaration of Alma-Ata. International Conference on Primary Health Care, Alma-Ata, USSR, 6-12 September 1978 [Internet]. World Health Organization [cited 2017 Oct 24]. Available from: http://www.who.int/publications/almaata_ declaration_en.pdf.

14. World Health Organization [Internet]. The Organization; 2018 [cited 2017 Oct 24]. The Ottawa Charter for Health Promotion. First International Conference on Health Promotion, Ottawa 21, November 1986. Available from: http:// www.who.int/healthpromotion/conferences/previous/ottawa/en/.
15. Decision No 1350/2007/EC of the European Parliament and of the Council of 23 October 2007 establishing a second programme of Community action in the field of health (200813) (Text with EEA relevance) [Internet]. Off J Eur Communities L 301 (Nov 20, 2007) [cited 2017 Oct 24]. Available from: http://eur-lex.europa.eu/LexUriServ/LexUriServ.do? uri=OJ:L:2007:301:0003:0013:EN:PDF.

16. Regulation (EU) No 282/2014 of the European Parliament and of the Council of 11 March 2014 on the establishment of a third Programme for the Union's action in the field of health (2014-2020) and repealing Decision No 1350/2007/ EC Text with EEA relevance [Internet]. Off J Eur Communities L 086 (Mar 21, 2014) [cited 2017 Oct 24]. Available from: http://eur-lex.europa.eu/legal-content/EN/TX $\mathrm{T} /$;jsessionid $=5 \mathrm{Qj} 3 \mathrm{TvyCyBqbhfLZzzBttjDGh3gyXkQ}$ WYrjhrt36mChMJJlp02XX!2060916514?uri=uriserv: OJ.L_.2014.086.01.0001.01.ENG.

17. Health and Food Safety - Strategic plan 2016-2020. DG Health \& Food Safety. Ref. Ares (2016)2075174 - 02/05/2016. [cited 2017 Oct 24]. Available from: https://ec.europa.eu/ info/sites/info/files/strategic-plan-2016-2020-dg-sante_ may2016_en.pdf.

18. Health in all policies: Helsinki statement. Framework for country action [Internet]. World Health Organization; 2014 [cited 2017 Oct 18]. Available from: http://apps.who.int/iris/ bitstream/10665/112636/1/9789241506908_eng.pdf?ua=1.

19. Leppo K, Ollila E, Peña S, Wismar M, Cook S, editors. Health in all policies. Seizing opportunities, implementing policies [Internet]. Finland: Ministry of Social Affairs and Health; 2013 [cited 2017 Oct 24]. Available from: http:// www.euro.who.int/_data/assets/pdf_file/0007/188809/ Health-in-All-Policies-final.pdf.

20. Ståhl T, Wismar M, Ollila E, Lahtinen E, Leppo K, editors. Health in all policies. Prospects and potentials [Internet]. Helsinki: Ministry of Social Affairs and Health and European Observatory on Health Systems and Policies; 2006 [cited 2017 Oct 24]. Available from: http://hiaconnect.edu.au/old/ files/Health_in_All_Policies.pdf. 
21. Pinto BM, Goldstein MG, DePue JD, Milan FB. Acceptability and feasibility of physician-based activity counseling: The PAL project. Am J Prev Med. 1998;15(2):95-102, https://doi. org/10.1016/S0749-3797(98)00043-9.

22. Kottke TE, Blackburn H, Brekke ML, Solberg LI. The systematic practice of preventive cardiology. Am J Cardiol. 1987; 59(6):690-4, https://doi.org/10.1016/0002-9149(87)91195-7.

23. Charles E. Lewis CE, Wells KB, Ware J. A model for predicting the counseling practices of physicians. J Gen Intern Med. 1986;1(1):14-9, https://doi.org/10.1007/BF02596319.

24. Williams PA, Williams M. Barriers and incentives for primary-care physicians in cancer prevention and detection. Cancer
[Internet]. 1987 [cited 2017 Oct 24];60(8 Suppl):1970-8. Available from: http://onlinelibrary.wiley.com/doi/10.1002/ 1097-0142(19901015)60:8+\%3C1970::AID-CNCR2820601 508\%3E3.0.CO;2-M/epdf.

25. Mirand AL, Beehler GP, Kuo CL, Mahoney MC. Physician perceptions of primary prevention: Qualitative base for the conceptual shaping of a practice intervention tool. BMC Public Health. 2002;2:16, https://doi.org/10.1186/1471-2458-2-16. 26. Lobelo F, de Quevedo IG. The evidence in support of physicians and health care providers as physical activity role models. Am J Lifestyle Med. 2016;10(1):36-52, https://doi. org/10.1177/1559827613520120.

This work is available in Open Access model and licensed under a Creative Commons Attribution-NonCommercial 3.0 Poland License - http://creativecommons.org/ licenses/by-nc/3.0/pl/deed.en. 